\title{
Physicochemical, thermodynamic and thermal properties of linalyl acetate-ethanol-water system
}

\author{
Vanya Gandova ${ }^{1}$, Stanislava Tasheva ${ }^{1, *}$, Krasimira Dobreva ${ }^{2}$, Vanya Prodanova- \\ Stefanova $^{2}$, Krasimira Marinova ${ }^{3}$, and Albena Stoyanova ${ }^{1}$ \\ ${ }^{1}$ University of Food Technologies, Plovdiv, 4002, Bulgaria \\ ${ }^{2}$ Trakia University, Dept. Food Technology, Yambol, 8600, Bulgaria \\ ${ }^{3}$ University Prof. Dr. Assen Zlatarov-Burgas, Central scientific research laboratory, 8010, Bulgaria
}

\begin{abstract}
Some physicochemical, thermodynamic and thermal properties of linalyl acetate - ethanol - water solutions with different ethanol concentrations $(70 \%, 75 \%, 80 \%, 85 \%, 90 \%$, and $95 \%)$ in three ratios $(1: 5$, $1: 6$, and 1:7) were determined. The properties were calculated to describe the stability of the system. Multiply linear regression model was obtained for surface tension prediction. Good correlation was observed between calculated and experimental surface tension values.
\end{abstract}

\section{Introduction}

Linalyl acetate $\left(\mathrm{C}_{12} \mathrm{H}_{20} \mathrm{O}_{2}, \mathrm{M}_{\mathrm{t}} 196,29, \mathrm{bp}_{101,3 \mathrm{kPa}} 220^{\circ} \mathrm{C}, \mathrm{n}_{D}^{20} 251.4480\right)$ occurs as its (-)isomer as the main component of many essential oil, for example lavender, lavandin, bergamot, clary sage, etc. $( \pm)$-Linalyl acetate is synthesized by two methods: esterification of linalool and convertion of dehydrolinalool. It is a colorless liquid with a distinct bergamot lavender odor. Linalyl acetate is an excellent fragrance material for perfumery products, soaps and detergents [1]. Linalyl acetate has antimicrobial action [2-6] and antiinflammatory activity [7].

In the European Cosmetic Directive is in the list of allergens as natural constituent of plant essential oil or other natural flavoring. These allergens must not exceed the permissible concentration of $0.01 \%$ in shower gels and rinse-off products and must not be higher than $0.001 \%$ in body oils, massage oils and creams. Sarkic and Stappen [8] reported for dermatitis of the linalool and linalool derivates.

Some physicochemical and thermodynamic properties were studied from different authors. Density, viscosity, refractive index and surface tension in different system and at different temperatures were determined [9-12]. A mathematical model was using to investigate physicochemical properties as surface tensions. The model was based on the multiple linear regressions fits $[13,14]$. The thermal properties were investigated and presented by [15-17].

\footnotetext{
* Corresponding author: st tasheva@abv.bg
} 
The aim of this research is an experimental and theoretical study on the some properties for oil dissolve in solutions with different ethanol concentrations and application in different areas.

\section{Material and methods}

\subsection{Materials}

All solutions are prepared with distilled water. ( \pm )-Linalyl acetate was provided by $\mathrm{F}$. Hoffmann la Roche $\left(\mathrm{n}_{D}^{20} 1.4630\right)$ and $95 \%$ ethanol by FILLAB, Bulgaria.

\subsubsection{Experiments and procedures}

It is determined the surface tension of 18 samples of linalyl acetate:ethanol mixture. Six series of experiments are prepared. The prime composition of all samples is presented in Table 1. From the 95\% starting ethanol, 70\%, 75\%, 80\%, 85\%, 90\% ethanol are diluted with distilled water. The preparation of solutions and the experimental procedure are described [18].

Table 1. Prime composition of three components for of linalyl acetate - ethanol - water system.

\begin{tabular}{|c|c|c|c|c|}
\hline Sample & ratio: linalyl acetate - ethanol & Linalyl acetate, $\%$ & Ethanol, $\%$ & Water, $\%$ \\
\hline 1 & $1: 5$ & 30 & 44 & 26 \\
\hline 2 & $1: 6$ & 25 & 47 & 28 \\
\hline 3 & $1: 7$ & 20 & 50 & 30 \\
\hline 4 & $1: 5$ & 30 & 50 & 20 \\
\hline 5 & $1: 6$ & 25 & 54 & 21 \\
\hline 6 & $1: 7$ & 20 & 57 & 23 \\
\hline 7 & $1: 5$ & 30 & 56 & 14 \\
\hline 8 & $1: 6$ & 25 & 59 & 16 \\
\hline 9 & $1: 7$ & 20 & 64 & 16 \\
\hline 10 & $1: 5$ & 30 & 60 & 10 \\
\hline 11 & $1: 6$ & 25 & 65 & 10 \\
\hline 12 & $1: 7$ & 20 & 69 & 11 \\
\hline 13 & $1: 5$ & 30 & 64 & 6 \\
\hline 14 & $1: 6$ & 25 & 69 & 6 \\
\hline 15 & $1: 7$ & 20 & 73 & 7 \\
\hline 16 & $1: 5$ & 30 & 70 & 0 \\
\hline 17 & $1: 6$ & 25 & 75 & 0 \\
\hline 18 & $1: 7$ & 20 & 80 & 0 \\
\hline
\end{tabular}

\subsubsection{Infrared spectroscopy of linalyl acetate}

The infrared spectrum was recorded using a Nicolet iS 50 Thermo Scientific FT-IR spectrometer in the frequency region of $4000-400 \mathrm{~cm}^{-1}$, with the samples presented in $\mathrm{KBr}$ matrixes.

To obtain model for surface tension prediction the multiple linear regression method was applied. Some thermodynamic and thermal properties were calculated to determine the stability of the system. The obtained surface tension model and thermodynamic and thermal properties were described from authors [14]. The studied physicochemical properties of the 
solutions (density, refraction and surface tension) are performed at the temperature of $25{ }^{\circ} \mathrm{C}$ and the pressure of $1.10^{5} \mathrm{~Pa}$ (atmosphere pressure).

The thermodynamic parameters (free energy of Gibb's, entropy, enthalpy, and activation energy) are criterion for thermodynamic stability of system. The calculations for thermodynamic parameters were given for 1 mol according $[16,19]$.

\subsection{Calculation}

Specific heat capacity, thermal conductivity and diffusivity were determined according [20].

The reaction rate theory for the dynamic viscosity [21-23] according Eyring was determined by free energy of Gibb's with following equation:

$$
\mu=\frac{N \cdot h}{V} e^{\frac{\Delta G}{R \cdot T}}
$$

Where: $\mu$ is dynamic viscosity, Pa.s; $V$ is molar volume, $\mathrm{m}^{3} \cdot \mathrm{mol}^{-1} ; N$ is Avagadro's

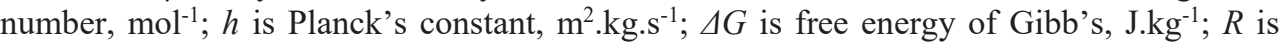
universal gas constant, $\mathrm{J}_{\mathrm{kg}^{-1}} \cdot \mathrm{K}^{-1}$ and $T$ is temperature, $\mathrm{K}$.

Between dynamic and kinematic viscosity appeared connection which presented for equation:

$$
v=\frac{\mu}{\rho}
$$

Where: $v$ is kinematic viscosity, $\mathrm{m}^{2} . \mathrm{s}^{-1} ; \mu$ is dynamic viscosity, Pa.s; $\rho$ is density at the corresponding temperature, $\mathrm{kg} \cdot \mathrm{m}^{-3}$.

\section{Results and discussions}

The experimental FT-IR spectrum of linalyl acetate is presents in Fig. 1. From the oil spectrum (Fig. 1) there is a clear line at $2972 \mathrm{~cm}^{-1}$ and $2930 \mathrm{~cm}^{-1}$, which is proof of linear $\gamma_{\text {as }} \mathrm{CH}_{3}$ и $\gamma_{\text {as }}-\mathrm{CH}_{2}$ - bonds. The bands at $3090 \mathrm{~cm}^{-1}$ and $1644 \mathrm{~cm}^{-1}$ responsible for the presence of $\gamma_{\mathrm{C}-\mathrm{H}}$ average absorption band, characteristic of $\mathrm{R}^{\prime} \mathrm{RC}=\mathrm{CH}_{2}$. There are also characteristic stripes $1739 \mathrm{~cm}^{-1}$, corresponding to oscillation of $\gamma \mathrm{C}=\mathrm{O}$ conjugated aliphatic esters. A distinctive characteristic strip is outlined $1249 \mathrm{~cm}^{-1}$, characteristic of an ester, which is further confirmed by the strip $1110 \mathrm{~cm}^{-1}, 1044 \mathrm{~cm}^{-1}$ and $1092 \mathrm{~cm}^{-1}$, typical of vinyl $=\mathrm{C}-\mathrm{O}-\mathrm{C}, \gamma^{\mathrm{s}} \mathrm{C}-\mathrm{O}-\mathrm{C}$. The IR spectrum of linalyl acetate is presents in Table 2 .

The experimental data for properties of solutions of $( \pm)$-linalyl acetate and ethanol are presented in Table 2. According the experimental results was obtained that with increasing of dilution, independent on concentration of ethanol, the values of density and surface tension decreasing but the values of refractive index increase. In solutions prepared with ethanol $95 \%$, observed some low values close to density and surface tension of pure ethanol at temperature $20{ }^{0} \mathrm{C}\left(\rho_{1}=0,789 \mathrm{~kg} \cdot \mathrm{m}^{-3}\right.$ and $\left.\gamma=22,80 \mathrm{mN} \cdot \mathrm{m}^{-1}\right)$ [19].

Table 2. The IR spectrum of linalyl acetate.

\begin{tabular}{|c|c|c|}
\hline \multicolumn{2}{|c|}{ Characteristic bands, $\mathrm{cm}^{-1}$} & \\
\cline { 1 - 2 } Linalyl acetate & Reference data & Group type \\
\hline 3455 & $\begin{array}{c}550-3400 \\
3590-3420\end{array}$ & $\gamma \mathrm{OH}$ intramolecular $\mathrm{H}-$ bond \\
\hline
\end{tabular}




\begin{tabular}{|c|c|c|}
\hline 3090 & $3095-3075$ & $\gamma_{\mathrm{C}-\mathrm{H}}$ average absorption band characteristic of $\mathrm{R}^{\prime} \mathrm{RC}=\mathrm{CH}_{2}$ \\
\hline 2972 & $2970-2950$ & linear $\gamma_{\text {as }} \mathrm{CH}_{3}$ \\
\hline 2930 & $2940-2915$ & $\gamma_{\text {as }}-\mathrm{CH}_{2}-$ \\
\hline 1739 & $1740-1720$ & $\gamma \mathrm{C}=\mathrm{O}$ conjugated aliphatic esters \\
\hline 1644 & $1648-1640$ & non-conjugated $\mathrm{C}=\mathrm{C}$, low intensity. $\mathrm{HRC}=\mathrm{CH}_{2}$ and vinyl \\
\hline 1450 & $1450-1250$ & some informative stripes $\delta(\mathrm{OH})$ for $\mathrm{R}-\mathrm{O}-\mathrm{H}$ \\
\hline 1413 & $1435-1405$ & $-\mathrm{CH}_{2}-\mathrm{CO}-$ vibrations of ketones, $\delta \mathrm{CH}_{2}$ \\
\hline 1368 & $1385-1370$ & a structural fragment of the type $\mathrm{C}\left(\mathrm{CH}_{3}\right)_{2}$ \\
\hline 1249 & $1260-1240$ & $\gamma^{\text {as }} \mathrm{C}-\mathrm{O}-\mathrm{C}$, ether bond \\
\hline 1173 & $1175-1165$ & absorption band characteristic of a group of type $\mathrm{CH}_{3}-\mathrm{CH}_{-}-\mathrm{CH}_{3}$ \\
\hline 1110 & $1150-1050$ & strip characteristic of the $\gamma^{\text {as }} \mathrm{C}-\mathrm{O}-\mathrm{C}$ bond \\
\hline 1092 & $1150-1050$ & strip characteristic of the $\gamma^{\text {as }} \mathrm{C}-\mathrm{O}-\mathrm{C}$ bond \\
\hline 1044 & $1070-1020$ & $=\mathrm{C}-\mathrm{O}-\mathrm{C}, \gamma^{\mathrm{s}} \mathrm{C}-\mathrm{O}-\mathrm{C}$, aromatic and vinyl \\
\hline 923 & $925-905$ & $\mathrm{C}-\mathrm{H}$ bond in alkenes of the type $\mathrm{HRC}=\mathrm{CH}_{2}$ \\
\hline
\end{tabular}

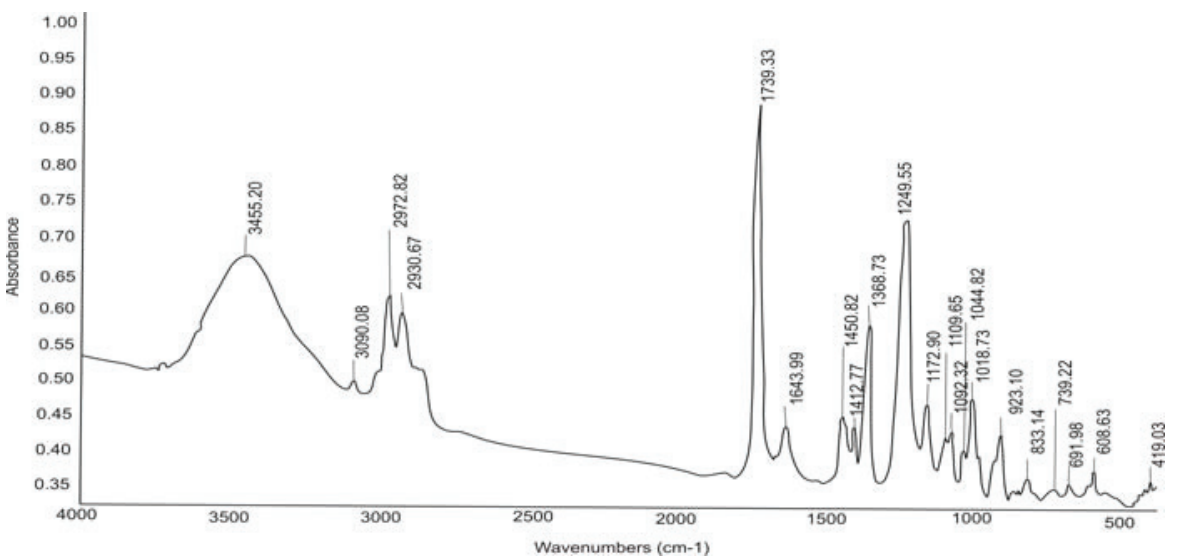

Fig. 1. IR spectrum of linalyl acetate essential oil.

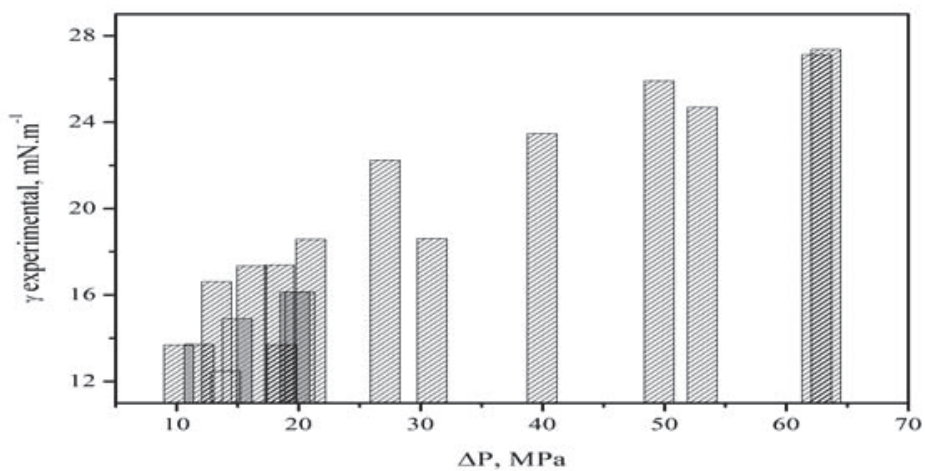

Fig. 2. Dependence of surface tension from Laplace pressure $\Delta \mathrm{P}$.

In Fig. 2 the dependences between experimental surface tension and Laplace pressure [14] are presented. It is observed good correlation between them. Small Laplace pressure was observed at small pressure in solutions with high percent ethanol. The studied 
physicochemical properties of the solutions (density, surface tension, and refraction) are presented in Table 3. The studies were performed at the temperature of $25{ }^{\circ} \mathrm{C}$ and the pressure of $1.10^{5} \mathrm{~Pa}$ (atmosphere pressure).

Table 3. Thermodynamic properties of linalyl acetate - ethanol - water solutions.

\begin{tabular}{|c|c|c|c|c|}
\hline Ethanol, \% & $\begin{array}{c}\text { ratio of ( } \pm \text {-linalyl acetate } \\
\text { - ethanol }\end{array}$ & $\begin{array}{c}\text { Density, } \\
\rho, 10^{-3} \mathrm{~kg}^{-3}\end{array}$ & $\begin{array}{c}\text { Surface tension, } \\
\gamma, \mathrm{mN} \cdot \mathrm{m}^{-1}\end{array}$ & $\begin{array}{c}\text { Refractive } \\
\text { index, } \mathrm{n}_{D}^{20}\end{array}$ \\
\hline 70 & $1: 5$ & 0.854 & 25.904 & 1.3788 \\
\hline 70 & $1: 6$ & 0.849 & 17.335 & 1.3783 \\
\hline 70 & $1: 7$ & 0.847 & 16.112 & 1.3768 \\
\hline 75 & $1: 5$ & 0.848 & 25.911 & 1.3803 \\
\hline 75 & $1: 6$ & 0.846 & 23.464 & 1.3792 \\
\hline 75 & $1: 7$ & 0.842 & 22.244 & 1.3717 \\
\hline 80 & $1: 5$ & 0.837 & 18.575 & 1.3807 \\
\hline 80 & $1: 6$ & 0.836 & 17.351 & 1.3789 \\
\hline 80 & $1: 7$ & 0.835 & 16.617 & 1.3771 \\
\hline 85 & $1: 5$ & 0.835 & 16.127 & 1.3820 \\
\hline 85 & $1: 6$ & 0.829 & 14.909 & 1.3794 \\
\hline 85 & $1: 7$ & 0.827 & 13.687 & 1.3772 \\
\hline 90 & $1: 5$ & 0.825 & 16.139 & 1.3815 \\
\hline 90 & $1: 6$ & 0.820 & 13.696 & 1.3808 \\
\hline 90 & $1: 7$ & 0.814 & 11.253 & 1.3782 \\
\hline 95 & $1: 5$ & 0.807 & 18.611 & 1.3818 \\
\hline 95 & $1: 6$ & 0.803 & 17.391 & 1.3859 \\
\hline 95 & $1: 7$ & 0.799 & 13.721 & 1.3789 \\
\hline
\end{tabular}

To estimate the surface tension from different pressures a multiple linear regression model was developed. The obtained linear regression based on the equations of authors [13, 14] for the Laplace pressure $\Delta \mathrm{P}$ and maximum bubble pressure.

It is determined the linear regression equations $\mathrm{y}=\mathrm{a}+\mathrm{b} . \mathrm{x}$, where $a$ and $b$ are constant, but $x$ is Laplace pressure $\Delta \mathrm{P}$.

$$
y=11.49+0.26 . x
$$

For eq. (3) the standard error was calculated for two constant $-\mathrm{a}= \pm 0.76$ and $\mathrm{b}= \pm$ 0.02 . The correlation coefficient $\left(R^{2}=0.891\right)$ and average value of the correlation coefficient (Adj. $R^{2}=0.885$ ) was determined.

Eq. (4) gives possibilities to determine the maximum bubble pressure values $P_{\max }$.

$$
y=-0.95+0.25 . x
$$

The same calculations were prepared as eq. in (4). The standard error for two constant are: $\mathrm{a}= \pm 0.01$ and $\left.\mathrm{b}= \pm 2.10^{-4}\right)$. The correlation coefficient $\left(\mathrm{R}^{2}=0.999\right)$ and average value of the correlation coefficient (Adj. $\left.\mathrm{R}^{2}=0.999\right)$ was present.

A high coefficient of correlation for eqs. 3 and 4 indicates the excellent correlation between experimental and calculated values. The standard error for each constants show a low error for the results.

The thermodynamic parameters Gibbs free energy, enthalpy and entropy were calculated for the obtained solutions. According different ethanol percent in solutions data are presented in Fig. 3. 


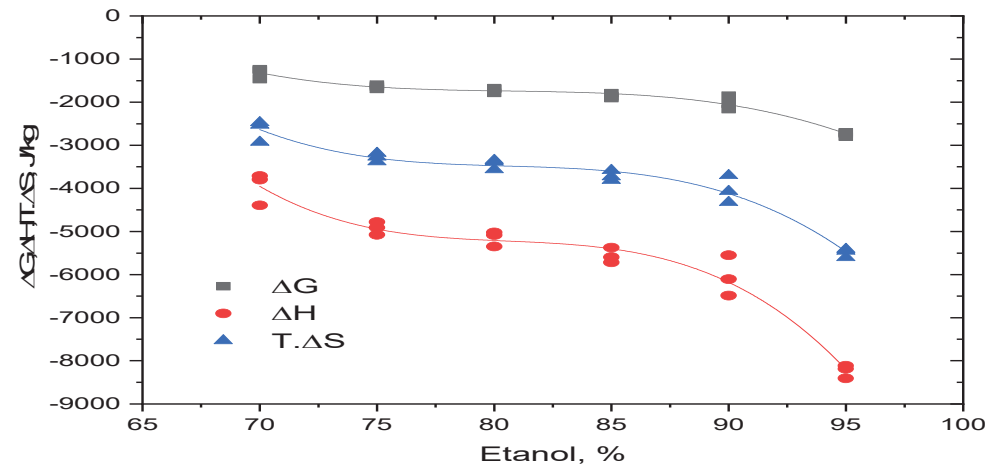

Fig. 3. Thermodynamic parameters of solutions linalyl acetate - ethanol - water system at different ethanol percent.

According graphical dependence from Fig. 3 all thermodynamic parameters are negative and process of dissolution is determined as a spontaneously and irreversible.

Based on the presented graphical dependence, third degree polynomial equations with the average correlation coefficients and the correlation coefficient of each equation are derived to determine the thermodynamic parameters depending on the ethanol concentration in the solution presented in Table 4. The activation energy is calculated too. The determined value is $\mathrm{E}_{\mathrm{a}}=-11.42 \mathrm{~kJ} \cdot \mathrm{mol}^{-1}$.

Table 4. Polynomial equations of solutions linalyl acetate - ethanol - water system.

\begin{tabular}{|c|c|c|}
\hline Equations & $\mathrm{R}^{2}$ & Stand. error \\
\hline$\Delta \mathrm{G}=151268-568357 . \mathrm{x}+704685 . \mathrm{x}^{2}-291633 . \mathrm{x}^{3}$ & 0.837 & \pm 0.02 \\
\hline$\Delta \mathrm{H}=454050-2.10^{6} \cdot \mathrm{x}+2.10^{6} \cdot \mathrm{x}^{2}-875374 . \mathrm{x}^{3}$ & 0.837 & \pm 0.06 \\
\hline $\mathrm{T} \Delta \mathrm{S}=302782-1.10^{6} \cdot \mathrm{x}+1.10^{6} \cdot \mathrm{x}^{2}-0.58 . \mathrm{x}^{3}$ & 0.837 & \pm 0.09 \\
\hline
\end{tabular}

For the linalyl acetate - ethanol -water system thermal parameters (specific heat capacity, thermal conductivity coefficient, thermal diffusivity coefficient, dynamic, and kinematic viscosity) are calculated and presented in Table 5.

Table 5. Thermal parameters of solutions linalyl acetate - ethanol - water system.

\begin{tabular}{|c|c|c|c|c|c|}
\hline $\begin{array}{c}\text { Ethanol, } \\
\%\end{array}$ & $\begin{array}{c}\text { Heat } \\
\text { capacity, } \\
\mathrm{c}, \mathrm{kJ} \cdot \mathrm{mol}^{-1} \cdot \mathrm{K}^{-} \\
1\end{array}$ & $\begin{array}{c}\text { Coefficient of } \\
\text { conductivity, } \\
\lambda .10^{3}, \mathrm{~W} \cdot \mathrm{m}^{-1} \cdot \mathrm{K}^{-1}\end{array}$ & $\begin{array}{c}\text { Coefficient } \\
\text { of thermal } \\
\text { diffusivity, } \\
\mathrm{a}, 10^{6}, \mathrm{~m}^{2} . \mathrm{s}^{-1}\end{array}$ & $\begin{array}{c}\text { Dynamic } \\
\text { viscosity, } \\
\mu .10^{12}, \mathrm{~Pa} . \mathrm{s}\end{array}$ & $\begin{array}{c}\text { Kinematic } \\
\text { viscosity, } \\
v .10^{15}, \mathrm{~m}^{2} . \mathrm{s}^{-1}\end{array}$ \\
\hline 70 & 35.90 & 330.36 & 10.78 & 22.51 & 26.36 \\
\hline 70 & 33.89 & 330.37 & 11.48 & 26.84 & 31.61 \\
\hline 70 & 32.10 & 330.37 & 12.15 & 30.32 & 35.78 \\
\hline 75 & 39.00 & 330.37 & 9.99 & 19.99 & 23.57 \\
\hline 75 & 37.15 & 330.37 & 10.51 & 22.44 & 26.52 \\
\hline 75 & 35.01 & 330.37 & 11.21 & 25.36 & 30.12 \\
\hline 80 & 42.69 & 330.37 & 9.25 & 18.65 & 22.29 \\
\hline 80 & 39.89 & 330.37 & 9.91 & 21.45 & 25.66 \\
\hline 80 & 38.50 & 330.37 & 10.38 & 23.48 & 28.12 \\
\hline 85 & 45.56 & 330.37 & 8.68 & 17.48 & 20.93 \\
\hline 85 & 43.76 & 330.38 & 9.11 & 19.28 & 23.26 \\
\hline
\end{tabular}




\begin{tabular}{|l|l|l|l|l|l|}
\hline 85 & 41.44 & 330.38 & 9.64 & 21.93 & 26.52 \\
\hline 90 & 48.85 & 330.38 & 8.20 & 15.38 & 18.64 \\
\hline 90 & 46.78 & 330.38 & 8.61 & 17.57 & 21.42 \\
\hline 90 & 44.15 & 330.38 & 9.19 & 20.76 & 25.50 \\
\hline 95 & 54.79 & 330.39 & 7.47 & 11.40 & 14.13 \\
\hline 95 & 52.20 & 330.39 & 7.88 & 12.86 & 16.02 \\
\hline 95 & 52.26 & 330.39 & 7.91 & 13.92 & 17.43 \\
\hline
\end{tabular}

From the data of Table 5 can be seen that with increasing of ratio linalyl acetate:ethanol in the solutions with the same percentage concentration of ethanol there is a decreasing in the specific heat capacity, and an increasing in the coefficient of thermal conductivity, as well as the dynamic and kinematic viscosity. This was explained by the fact that these coefficients are additive values and the chemical composition of the substance affects their values. Only the coefficient of thermal conductivity remains the same when the ratio of linalyl acetate: ethanol changes, which means that this coefficient is independent of the nature of the chemical composition of the substances.

In reference [14] are investigated physicochemical and thermal properties of the linalool. The three thermal parameters according calculations obtained in [14] work are: $\lambda=$ 0.33 W.m-1 K ${ }^{-1}, \mathrm{Cp}=2.7-3.8 \mathrm{\kappa J} \cdot \mathrm{mol}^{-1} \mathrm{~K}^{-1}$ and $\mathrm{a}=7.94 .10^{-6}-12.41 .10^{-6} \mathrm{~m}^{2} \cdot \mathrm{s}^{-1}$. The results can't compare with the data for the same parameters in this paper because linalool and linalyl acetate are two compounds with different functional groups: linalool is alcohol and linalyl acetate is ester. In this case it is normal to obtained different values for heat capacities.

\section{Conclusion}

Different properties of linalyl acetate-ethanol-water system with different ethanol concentrations $(70 \%, 75 \%, 80 \%, 85 \%, 90 \%$, and $95 \%)$ were determined. Infrared spectrum analysis was performed and surface tension for all solutions was measured. Multiply linear regression model was obtained for surface tension prediction. Good correlation was observed between calculated and experimental surface tension values. The thermodynamic parameters (Gibbs free energy, enthalpy and entropy) and thermal parameters (specific heat capacity, thermal conductivity coefficient, thermal diffusivity coefficient, dynamic and kinematic viscosity) were determined.

\section{References}

1. K. Bauer, D. Garbe, H. Surburg, Common fragrance and flavor materials. Preparation, properties and uses, fourth completely revised Edition, Weinheim, New York, Chichester, Brisbane, Singapore, Toronto, Wiley - VCH (2010)

2. K. Baser, G. Buchbauer, Handbook of essential oils: science, technology, and applications. Taylor and Francis Group, LLC CRC Press is an imprint of Taylor \& Francis Group, an Informa business (2010)

3. S. Griffin, G. Wyllie, J. Markham, D. Leach, Flavour and Fragr. Jour. 14, 322-332 (1999)

4. L. Jirovetz, G. Buchbauer, A. Stoyanova, Z. Denkova, I. Murgov, Euro Cosmertics 1, 30-33 (2004)

5. L. Jirovetz, G. Buchbauer, Z. Denkova, A. Stoyanova, I. Murgov, E. Schmidt, M. Geissler, HKB, Dehradun, India, 266-274 (2005) 
6. L. Jirovetz, K. Wlcek, G. Buchbauer, V. Gochev, A. Stoyanova, E. Schmidt, Int. Jour. of Essen. Oil Therap. 1, 61-66 (2007)

7. A.T. Peana, P. S. D'Aquila, F. Panin, G. Serra, P. Pippia1, and M. D. L. Maretti, Phytomedicine 9, 721-726 (2002)

8. A. Sarkic and I. Stappen, Cosmetics, 5, 11 1-21 (2018)

9. P. Florido, I. Andrade, M. Capellini, F. Carvalho, K. Aracava, C. Koshima, C. Rodrigues, C. Goncalves, J. Chem. Thermodyn. 72, 152-160 (2014)

10. R. Clará, A. Gómez Marigliano, V. del Campos, H. Sólimo, Fluid Phase Equilibria 293, 151-156 (2010)

11. M. S. Garcha-Abarrio, T. Marcos, M. Luisa Haya, S. Urieta, A. Mainar, J. Chem. Thermodyn. 43, 4 527-536 (2011)

12. A. Gok, F. Cebeci, H. Uslu, S. Kirbaslar, J. Chem. Eng. Data 56, 3 521-526 (2011)

13. E-A. Melo-Espinosa, Y. Sánchez-Borroto, M. Errasti, R. Piloto-Rodríguez, R. Sierens, J. Roger-Riba, A. Christopher-Hansen, Energy Procedia 57, 886-895 (2014)

14. S. Tasheva, V. Gandova, K. Dobreva, I. Dincheva, V. Prodanova-Stefanova, A. Stoyanova, RJPBCS 10, 6 220-227 (2019)

15. F. Incropera, D. Dewitt, T. Bergman, A. Lavine, Fundamentals of Heat and Mass Transfer 6th Edition. John Wiley \&Sons (2006)

16. H. Topallar, Ü. Geçgel, Turk Journal Chemical 24, 247-253 (2000)

17. W. Yang, S. Sokhansanj, J. Tang, P. Winter, Biosys. Eng. 82, 2 169-176 (2002)

18. R. Yankova, V. Gandova, M. Dimov, K. Dobreva,V. Prodanova-Stefanova, A. Stoyanova, Oxi. Comm. 3, 293-306 (2019)

19. J. Khan, M. Farooqui, S.H. Quadri, Rasayan J. Chem. 4, 4 944-946 (2011)

20. W. Yang, S. Sokhansanj, J. Tang, P. Winter, Biosis. Eng. 82, 2, 169-176 (2002)

21. P. Hlavac, M. Bozikova, J. Central Europa Agriculture, 14, 3, 1144-1157 (2013)

22. J-T Hung, J-S Tsaih, H-H Tang, Int. Refr. and Air Cond. Conf., 1474-1485 (2014)

23. S. Puttala1, S. Phankosol, T. Techapirom, T. Chum-in, K. Krisnangkura, IOP Conf. Series: Jour. of Phy.: Conf. Series 1144, 012184 (2018) 